\title{
EXPERIÊNCIA FORMATIVA MEDIATIZADA POR AMBIENTE VIRTUAL DE APRENDIZAGEM: formação de professores de Ciências e Matemática na Amazônia
}

\author{
FORMATIVE EXPERIENCE MEDIATED BY VIRTUAL LEARNING \\ ENVIRONMENT: science and mathematics teachers' education in the Amazon \\ Region
}

France Fraiha-Martins

Terezinha Valim Oliver Gonçalves

\section{RESUMO}

Este artigo expressa resultados de uma pesquisa de natureza qualitativa, na modalidade narrativa. Foram investigadas experiências formativas de professores de Ciências e Matemática a distância na Amazônia, vividas em um curso via Ambiente Virtual de Aprendizagem (AVA). Objetivamos investigar em que termos essa experiência formativa foi catalisadora de reflexões docentes sobre o contexto amazônico de ensino de Ciências e Matemática. Ao utilizarmos a Análise Textual Discursiva, emergiram as categorias: Formarse no contexto amazônico: obstáculos e enfrentamentos; Tecnologias e AVA: sentido(s) da experiência formativa; e As repercussões da experiência nas percepções da prática e da formação docente. Os resultados das análises revelam os obstáculos para formar-se nesse contexto. A dinâmica vivenciada por meio das tecnologias de um AVA e do coletivo de professores repercutiu em percepções metodológicas quanto ao uso das tecnologias nas práticas docentes, apontando também o AVA como alternativa de (auto) formação diante da realidade amazônica.

Palavras-chave: Ambiente Virtual de Aprendizagem. Educação Matemática e Científica. Formação Docente.

\begin{abstract}
This article reports results of a qualitative research, in the narrative modality. We investigated the formative experiences of teachers of Mathematics and Science through distance learning in the Amazon region, experienced in a course through the Virtual Learning Environment (VLE). We investigated under what conditions this education experience was a catalyst for teachers' reflections on the Amazonian context of teaching science and mathematics. By using Discursive Textual Analysis some categories emerged: Graduating in the Amazon region: obstacles and confrontations; AVA and Technologies: meaning (s) of the education experience and the impact of the experience in the perceptions of teachers' practices and training. The analysis of the results reveals the obstacles to the training in this context. The dynamics experienced by the use of VLE technologies and of the teachers reverberated methodological insights regarding the use of technology in teaching practices, indicating also the VLE as an alternative of (self) education on the Amazon reality.
\end{abstract}

Keywords: Virtual Learning Environment. Mathematical and Scientific Education. Teachers' Education. 


\section{INTRODUÇÃO}

São múltiplos os desafios que desestimulam e intimidam a formação continuada de professores de Ciências e Matemática no interior da Amazônia, seja pelas condições geográficas naturais da região, seja pela falta de infraestrutura.

A Amazônia, de grande extensão territorial, constitui a maior região geopolítica brasileira. Contudo, enfrentam-se grandes dificuldades de acesso a muitos municípios da região, por conta da precariedade de estradas e meios de transporte, assim como pelas distâncias que se maximizam com as inúmeras vias hídricas que caracterizam também esse contexto. Assim, para enfrentar os desafios geográficos e de infraestrutura, instituições de ensino superior tem lançado mão da EAD, a fim de reduzir tais problemáticas, buscando democratizar o acesso à formação profissional, sendo que grande parte dos cursos ofertados nessa modalidade limita-se a encontros presenciais condensados e a materiais impressos para estudos.

A perspectiva da formação a distância envolvendo Ambiente Virtual de Aprendizagem $^{1}$ (AVA) abriu novos horizontes para as oportunidades de acesso a ações de qualificação e profissionalização de professores de ciências e matemática na Amazônia, embora sua inclusão nas estratégias de cursos a distância ainda seja um enorme desafio frente a esse contexto. Trouxe, também, expectativas em relação ao processo de formação continuada docente que se insere como necessidade de aprender a aprender e conhecer em um mundo globalizado.

Nessa perspectiva, apresentamos o AVA como um novo/outro modelo de sala de aula que se insere - agregado a outros recursos da EAD - como modalidade para a formação de professores de ciências e matemática na região amazônica no intuito de induzir uma nova situação experimental, a fim de criar possibilidades de inclusão na nova cultura da sociedade da informação, a digital, buscando considerar a realidade local.

Esse ambiente, pelas características de suas ferramentas interativas, vem se constituindo como um espaço de formação de pessoas, utilizado tanto por empresas como pelas instituições de ensino. Para professores em formação, o AVA pode se configurar como um espaço formativo que potencialize o intercâmbio de experiências docentes, objetivando simultaneamente fortalecer a profissionalização do professor, construir conhecimentos e ressignificar suas práticas, além de dominar tecnologias, aprendendo a mover-se e intervir no espaço telemático (ALMEIDA, 2003).

É na perspectiva de enfrentamento dos obstáculos para formar-se no contexto amazônico, de ressignificação de práticas e de formação docente, que focamos esta pesquisa. Professores de Ciências e Matemática do Ensino Fundamental, no interior da Amazônia, ao vivenciarem uma experiência formativa, por meio de um AVA, desenvolvem percepções de suas próprias práticas que repercutem em ideias diferenciadas. Nesse sentido, ao trazermos à tona as vozes dos professores-alunos envolvidos nesta pesquisa, temos clara intenção de expressar que as ideias expostas são apenas algumas dentre as inúmeras interpretações possíveis. Importa-nos compartilhar esta experiência investigativa no intuito de gerar contraleituras e suscitar reflexões que possam materializar-se em ações que beneficiem a qualidade de ensino de ciências e matemática no contexto investigado.

\section{O CONTEXTO DA PESQUISA}

\footnotetext{
${ }^{1}$ Salas de aula virtuais disponíveis na internet. Permitem integrar múltiplas mídias, desenvolver interações entre pessoas e objetos de conhecimento, socializar produções, tendo em vista atingir determinados objetivos.
} 
Desenvolvemos a investigação envolvendo professores-alunos da especialização a distância em educação em Ciências e Matemática no âmbito do Programa EDUCIMAT². O Programa EDUCIMAT integra a Rede Nacional de Formação Continuada de Professores de Educação Básica (MEC/SEB) e visa à formação continuada de professores para a Educação Matemática e Científica, buscando atender ao Estado do Pará, constituinte da região Amazônica.

Após experiências docentes que vivemos no âmbito desse Programa, decidimos ofertar gratuitamente a esse grupo de professores-alunos - aqueles que manifestaram interesse - um curso de extensão a distância por meio do AVA TelEduc ${ }^{3}$, denominado Tutoria em Ambiente Virtual de Aprendizagem. Dos 39 (trinta e nove) professores-alunos existentes na turma do curso de especialização, 36 (trinta e seis) se inscreveram no curso de extensão. Desses, 19 (dezenove) participaram e 11 (onze) concluíram o curso. Todos oriundos de municípios do oeste do Estado.

Ao atuarmos como formadoras no referido curso, passamos por um processo de intensa reflexão e imersão no contexto vivido, o que resultou na construção do problema de pesquisa que expressamos do seguinte modo: Que sentidos e significados emergem das percepções de professores de Ciências e Matemática, ao refletirem sobre uma experiência formativa em Ambiente Virtual de Aprendizagem?

Partindo do problema mais amplo, buscamos responder algumas questões de investigação, quais sejam: Em que termos essa experiência formativa, mediada pelas tecnologias de um AVA, é catalisadora de reflexões docentes sobre o contexto amazônico de ensino de Ciências e Matemática? Que outras/novas aprendizagens formativas resultantes dessa experiência repercutem em percepções diferenciadas sobre a prática docente?

Portanto, pretendemos compreender, de que modo a vivência em um curso diferenciado, por sua modalidade de oferta e por ter proporcionado aproximação aos recursos tecnológicos (especificamente computador e internet), marcou, refletiu, tocou a percepção dos docentes investigados com respeito às possibilidades oferecidas pelas Tecnologias de Informação e Comunicação - TIC - em processos de formação continuada frente às suas necessidades e ao contexto amazônico. Dito de outra maneira: em que termos possibilitou (auto) formação.

\section{NOSSAS OPÇÕES METODOLÓGICAS}

Fazemos a opção por um percurso investigativo de caráter qualitativo, na modalidade narrativa, assumindo, com Connelly e Clandinin (1995, p.26), que, como método de investigação, a narrativa tem a "capacidade de reproduzir as experiências da vida, tanto pessoais como sociais de forma relevante e plenas de sentido". Ao contá-las, expressamos como experimentamos o mundo e, ainda, o que nos dizem dele e de nós mesmos.

Trazemos para este espaço comunicativo as vozes de seis professores-alunos, dos nove investigados, os quais chamamos ficticiamente de Carol, Hélia, Júlia, Wal, Joana e Eddy. Professores de Ciências e Matemática nos municípios de Oriximiná, Santarém, Prainha e Rurópolis. Todos localizados a oeste, no Estado do Pará e integrantes da região amazônica.

\footnotetext{
${ }^{2}$ Programa desenvolvido pelo então Núcleo de Pesquisa e Desenvolvimento da Educação Matemática e Científica NPADC/UFPA.

3 O ambiente TelEduc foi produzido pela UNICAMP e é disponibilizado gratuitamente para uso. http://teleduc.nied.unicamp.br
} 
Os critérios que adotamos para a escolha dos sujeitos foram os seguintes: serem professores-alunos do curso de especialização em Educação em Ciências e Matemática do Programa EDUCIMAT que ensinam ciências e matemática; terem mantido elevado nível de envolvimento nas interações ocorridas no AVA - a frequência de acesso e a participação nas diversas ferramentas disponibilizadas no ambiente - e, por fim, terem expressado ideias completas de modo reflexivo.

Optamos por utilizar como instrumento de investigação, além de nosso diário de campo, os depoimentos dos sujeitos expressos em entrevista semiestruturada, realizada no local de residência/trabalho de cada sujeito, no intuito de provocá-los a manifestar sentidos e significados por eles atribuídos à experiência formativa vivenciada no contexto do AVA. As vozes dos sujeitos foram gravadas em áudio e posteriormente transcritas.

Apropriamo-nos da Análise Textual Discursiva, que corresponde a uma metodologia de análise de dados qualitativos, buscando produzir novas compreensões sobre as narrativas investigadas (MOARES e GALIAZZI, 2007). Ao examinar o corpus $^{4}$, por meio da desconstrução ${ }^{5}$, unitarização ${ }^{6}$ e categorização dos textos, buscamos núcleos de sentido, que possibilitaram compreensão mais profunda acerca das narrativas dos sujeitos sobre a experiência vivida no curso via AVA. Desse modo, emergiram três categorias de análise, nomeadas de eixos temáticos: FORMAR-SE NO CONTEXTO AMAZÔNICO: obstáculos e enfrentamentos; TENOLOGIAS E AVA: sentido(s) da experiência formativa; e $A S$ REPERCUSSÕES DA EXPERIÊNCIA NAS PERCEPÇÕES DA PRÁTICA E DA FORMAÇÃO DOCENTE.

Compreendendo com JOSSO (2004, p.38) que "as narrativas de formação nos servem de material para compreender os processos de formação, de conhecimento e de aprendizagem", passamos, a seguir, a discutir/apresentar os eixos a que nos referimos, emersos das vozes dos professores-alunos envolvidos nesta investigação.

\section{FORMAR-SE NO CONTEXTO AMAZÔNICO: obstáculos e enfrentamentos}

Explicitamos, neste eixo temático, as várias dificuldades expressas pelos sujeitos investigados para formar-se continuamente na região amazônica. Os obstáculos enfrentados pelos professores-alunos recaem sobre as dificuldades de acesso à formação, à informação, bem como sobre as condições de acesso aos municípios, caracterizadas pelas grandes distâncias geográficas dos centros de formação e por dificuldades de transporte, como dito anteriormente.

A dificuldade de acesso à formação, manifestada pelos sujeitos, ocorre pelo fato de que poucas instituições educacionais ofertam cursos de graduação, extensão e pósgraduação na região. Isso parece ocorrer, de acordo com Silva (2005), a despeito da grandeza territorial e dos desafios da complexidade organizacional de promover cursos no interior da Amazônia. $\mathrm{O}$ autor refere-se às distâncias geográficas entre os municípios e ao elevado custo operacional para os promotores, exigindo uma logística robusta para tornar-se realidade. Para buscar um atendimento mais abrangente da população local, o autor enfatiza que as instituições federais de ensino superior (IFES) da Amazônia precisam ultrapassar o modelo de interiorização unicamente centrado no ensino presencial, "que tem exigido o deslocamento

\footnotetext{
${ }^{4}$ Conjunto de documentos - produções textuais - que representam as informações da pesquisa, que, neste caso, são os depoimentos transcritos.

${ }^{5}$ É um processo de desmontagem dos textos destacando seus elementos constituintes. Significa colocar o foco nos detalhes.

${ }^{6}$ Unidade de significado ou de sentido. Surge a partir da desconstrução do texto.
} 
intenso de professores dos campi das capitais para o interior dos estados e tem onerado o orçamento de custeio, em virtude das longas distâncias" (SILVA, 2005, p.35).

Assim, as condições geográficas e o acesso a determinados municípios configuram um dos obstáculos para formar-se continuamente no interior da Amazônia. A professora Wal ao se pronunciar a respeito de ser professora de Ciência na Amazônia comenta: a dificuldade que encontramos são muitas devido à extensão territorial. As comunidades longe de Belém e Santarém às vezes sofrem por isso. Por exemplo, os livros didáticos quando chegam para nós aqui, o ano letivo já começou.

Para enfrentar o obstáculo relativo a pouca oferta de cursos na região, os profissionais de municípios mais distantes dos centros de formação, precisam deslocar-se para outros municípios - denominado polos -, nos quais as instituições educacionais de nível superior se instalam para atender à demanda dos arredores. Como manifesta a professora Hélia: aqui dificilmente você encontra órgãos que financiem estudos e há pouca oferta de cursos. Se quisermos participar de formação continuada, precisamos buscar por conta própria e, ainda, fora do município.

Segundo Meirelles (2006), a falta de recursos para investimento em formação/educação da população integrante da região amazônica e a escassez de empreendimentos em pesquisas científicas nesse contexto são razões que ampliam as várias mazelas lá existentes. Como bem enfatiza, "sem ciência, tecnologia e educação superior de bom nível, é impossível colocar a Amazônia em um nível de desenvolvimento adequado" (MEIRELLES, 2006, p.154).

A respeito da dificuldade de acesso à informação, os professores-alunos destacam a pouca infraestrutura de materiais para estudo e pesquisa. Atrelam a essa escassez o difícil acesso às TIC, principalmente o acesso à internet, o que os impede, de certo modo, de ter acesso às informações difundidas e discutidas no mundo globalizado, uma vez que as TIC mais acessíveis nos municípios da região pesquisada limitam-se aos canais televisivos abertos e às rádios comunitárias que majoritariamente restringem-se às informações locais.

A professora Wal manifesta indícios de que valoriza a necessidade do acesso à informação por meio da internet em sua profissão docente, ao mencionar que a tecnologia [internet] é muito importante dentro do nosso contexto porque antes nós vivíamos isolados das informações que aconteciam lá fora. Hoje, posso buscar informações na internet que me ajudem a enriquecer minhas aulas. Wal parece evidenciar a pouca infraestrutura de materiais para pesquisa e ensino em sua região, demonstrando a compreensão de que, ao ter a oportunidade de acesso à internet em seu município, passou a não mais se sentir isolada das informações que circulam no âmbito global, além de considerar a rede digital, uma fonte de pesquisa.

Wal, ao relacionar o acesso à informação à sua prática docente, parece ir ao encontro da proposição de que informação e formação estão diretamente associadas, pois, pelas características do contexto, a informação parece chegar aos professores no instante em que estes estão inseridos em processos de formação continuada. Nesse sentido, Júlia assim se manifesta: o curso de especialização do EDUCIMAT nos encheu de informações. A muitas coisas não temos acesso. O estudo sobre educação inclusiva é um exemplo. Assim, é possível a compreensão de que não há como dissociar da prática desses docentes, informação da formação, ambos estão intrinsecamente ligados.

Nessa perspectiva, a EAD apoiada por AVA, temática tratada nesta pesquisa, pode constituir-se como modalidade de formação docente possível de oferecer informação ao tempo de oportunizar formação, pois diante dos enfrentamentos evidenciados pelos docentes 
pesquisados, podemos dizer que na realidade amazônica há que se pensar em formação, informação e TIC de maneira articulada, no intuito de minimizar os obstáculos peculiares e as problemáticas da região e maximizar as ofertas de formação continuada de professores de Ciências e Matemática, trazendo como um dos pressupostos a inclusão dos professores em formação, em um processo tecnologicamente mediado.

\title{
TECNOLOGIAS E AVA: sentido(s) da experiência formativa
}

Ao assumirmos a pesquisa qualitativa por meio da abordagem biográfica, buscamos nas narrativas orais dos professores-alunos, para realizar múltiplas interpretações que trouxessem à tona os sentidos que os sujeitos atribuíram à experiência formativa vivida no AVA. Por compreender, com Ferrarotti (1988), que a narrativa biográfica é de natureza relacional e de intencionalidade comunicativa, buscamos evidenciar, por meio das histórias contadas, aspectos oriundos dessa experiência que, em maior ou menor grau, constituíram processos de (auto) formação dos sujeitos investigados.

Os professores-alunos ao trocarem, experimentarem e interagirem em múltiplas relações (MOITA, 2000) provocaram reflexões/aprendizagens que, interpretadas à luz de referenciais teóricos por nós adotados, materializaram-se em sentidos de autoconhecimento, de constituir-se professor num mundo marcado pelos avanços tecnológicos, além de dar forma a um sentido de superação no uso das tecnologias que surpreende e (trans)forma.

Ao buscarmos compreender alguns dos sentidos da experiência formadora no AVA para Eddy, pudemos destacar de seu depoimento, percepções de si que foram mobilizadas durante o processo de formação. Conforme narra:

\begin{abstract}
Quando eu passei a conhecer um ambiente virtual de aprendizagem, comecei a ter uma visão maior, mais ampla. Consegui estabelecer várias relações, tanto a respeito da minha aprendizagem, quanto sobre a forma de ensinar. Quando você está no ambiente virtual, você é senhor de si, você tem que querer, acima de tudo, $e$ nós não estamos acostumados a isso. [...] Eu passei a me cobrar mais enquanto professor com relação à busca de conhecimento por conta própria, para melhorar a minha prática, apesar de acreditar que já fazia isso de alguma forma.
\end{abstract}

A experiência vivenciada por Eddy, no ambiente virtual, parece tê-lo levado a um processo de autoconhecimento. Ao mesmo tempo em que conhece seu objeto de estudo, reconhece-se diante do estudado. Santos (2005) aponta em sua terceira tese do paradigma emergente para uma vida decente, que todo conhecimento é autoconhecimento. Na medida em que Eddy estabeleceu relações de aprendizagens ao conhecer o AVA, e, ao identificar características que vê como necessárias ao aprendente em um ambiente virtual, concomitantemente, viveu um processo de autorreflexão sobre sua postura como aluno e professor, percebendo-se com certas atitudes autônomas, como se refere. Entretanto, passou a cobrar mais de si, o que implica a vontade de continuar a crescer, a se desenvolver profissionalmente.

Sob outro ponto de vista, constituir-se professor na era das tecnologias da informação e comunicação é motivo de preocupação e atenção dispensada pelos sujeitos investigados. A recorrência em seus depoimentos de que é necessário formar-se no uso das tecnologias educacionais, tendo em vista suas práticas docentes, configura outro sentido atribuído pelos sujeitos, embora por condições históricas, políticas e sociais, isso não tenha ocorrido com todos os professores-alunos investigados.

A professora Júlia manifesta tal sentido ao expressar-se sobre o uso da internet para planejar suas atividades: 
Quando eu tenho necessidade de procurar alguma informação diferenciada que possa contextualizar o assunto abordado, eu recorro à Internet porque ela pode me proporcionar isso. Nós, como professores, temos que estar inteiramente ligados às tecnologias, sim. Temos que estar, como dizem os alunos, "antenados”. Ser professor de matemática é estar ligado com o mundo, com as coisas que estão evoluindo.

Júlia, que, desde o início, demonstrou ser usuária experiente no uso do computador e internet, enfatiza sua preocupação em tentar acompanhar os avanços tecnológicos que a cercam, de modo a contribuir com sua prática docente, embora tenha explicitado em outros relatos que no local onde atua profissionalmente ainda não dispõe de nenhum acesso.

A recorrência da necessidade de formar-se no uso dessas tecnologias com vistas às práticas docentes, também evidenciada por outros sujeitos, nos parece instituída nos discursos por meio do 'senso comum', como algo que necessita apenas de processos formativos técnicos e condicionantes. Tal premissa nos leva a apresentar algumas proposições.

A preocupação referida por Júlia com respeito a ser professora de matemática e estar ligada com o mundo, com as coisas que estão evoluindo, assenta-se na discussão, já referida, quanto aos modelos digitais e novos instrumentos tecnológicos (MORAES, 1997; ASSMANN, 2000). Esses aspectos vêm configurando o contexto tecnológico globalizado atual, chamado, por Green e Bigum (2001), de ecologia digital e provocando novas exigências, no que se refere ao uso de recursos associados, de telecomunicação e computacionais, na sociedade da informação.

A respeito dessa discussão, Almeida (2007) destaca que o setor educacional vem enfrentando fortes pressões das demandas da sociedade pela preparação de cidadãos aptos a atuar na sociedade informatizada, incluindo os professores. Contudo, Sacristán (2002, p.66) chama atenção de que não devemos cair no encantamento ingênuo de dar por certo que "o progresso tecnológico traz necessariamente o humano e o social [refere-se à cultura e à educação]".

Nesse sentido, é necessário desenvolver no indivíduo - em especial, referimo-nos nesta pesquisa aos professores - a "curiosidade crítica, insatisfeita, indócil", a fim de se defender dos "irracionalismos decorrentes do ou produzidos por certo excesso de racionalidade de nosso tempo altamente tecnologizado" (FREIRE, 2007, p. 32). Assim, é importante que os professores tornem-se atores conscientes de seus papéis, intervindo e responsabilizando-se pelas representações das tecnologias educacionais que (re) produz.

O sentido de superação no uso das tecnologias também emergiu no processo de análise. Tal sentido, apontado pelos professores-alunos, demonstra que a experiência do uso das tecnologias - em especial computador e internet - ao mesmo tempo forma, surpreende e transforma as percepções dos sujeitos envolvidos.

Carol desenvolve relações entre a experiência formativa vivenciada no curso via AVA e sua aproximação com as tecnologias do computador e internet:

O primeiro dia foi difícil, pedi inicialmente ajuda. Já na segunda atividade, eu consegui ligar a internet, solicitar o que eu queria. Naquele momento eu me senti muito realizada porque eu me senti mais incentivada em saber que eu sou capaz de fazer acontecer. Essa aproximação com o computador foi uma forma de incentivo para que eu mudasse também um pouco a minha maneira de ensinar. Com isso, através desse curso no AVA eu evoluí muito na parte tecnológica, porque eu não tinha quase habilidade. 
Por meio do processo de formação pelo qual estava passando, Carol viveu instantes de conhecimento e reconhecimento de si. Mesmo constrangida pelo receio do não domínio do computador/internet, optou por seguir adiante, demonstrando compreender que ela própria é o agente principal da sua formação. Ao tomar a decisão de construir-se a si própria, enfrentando os desafios interiores, assume-se sujeito de sua aprendizagem.

Moita (2007, p. 115), ao tratar da formação docente, traduz o processo de formação como uma dinâmica em que a identidade de uma pessoa vai se construindo. Segundo seus próprios termos, a formação é um "processo em que cada pessoa, permanecendo ela própria e reconhecendo-se a mesma ao longo da sua história [da experiência formadora], se forma, se transforma, em interação". Carol, ao conseguir ligar a internet e realizar a atividade proposta, sentiu-se verdadeiramente em processo de formação, o que a motivou para se sentir capaz de fazer acontecer.

\title{
AS REPERCUSSÕES DA EXPERIÊNCIA NAS PERCEPÇÕES DA PRÁTICA E DA FORMAÇÃO DOCENTE
}

As repercussões da experiência formadora nas percepções da prática manifestadas pelos professores-alunos incidem sobre as possibilidades de uso das TIC como ferramentas pedagógicas. Dentre elas, foram destacados: o uso da internet como fonte de informação; o AVA como apoio às aulas presenciais; o uso de softwares educativos para aprender conteúdos matemáticos e científicos. Além disso, outras percepções apontam para a preocupação com a interatividade, troca de experiências e diálogos em situações de ensino presenciais, ao estabelecerem relações com o vivido na experiência formativa a distância. Manifestaram também a percepção de uma dinâmica de formação continuada que se desenvolve e se constrói pela diversidade de ideias. Neste artigo, fazemos a opção por apresentar algumas das percepções expressas acerca da possibilidade de uso das TIC e da contínua formação tecida pela multiplicidade de ideias por meio de um espaço virtual.

A formação no AVA, pelo caráter desconhecido dos recursos e da dinâmica de um ambiente virtual expresso pelos próprios professores-alunos, aproximou-os ainda mais das TICs, além de ampliar a compreensão das possibilidades de uso na ação educativa. Assim, manifesta-se a professora Wal:

\begin{abstract}
Outra aprendizagem que me marcou é o fato de eu ter me estimulado a trazer outras informações para os alunos, além do livro didático. Eu vejo a importância de apresentar os conteúdos de várias maneiras. Pode ser na Internet para que eles conheçam melhor o mundo virtual, através da TV escola ou um vídeo. Pensei: assim como eu me empolguei aprendendo pela internet, eles também podem se motivar se eu tentar diferenciar a forma de mostrar os assuntos.
\end{abstract}

A professora Wal, ao manifestar-se, nos termos: eu vejo a importância de apresentar os conteúdos de várias maneiras, parece ter compreendido que o fato de abordar os conteúdos de diversas formas, através de mídias diferentes, pode facilitar o entendimento e motivar o aluno durante o processo de aprendizagem. Seguindo o pensamento de Wal, Joana também considera importante utilizar várias mídias e assuntos afins, como forma de chegar até o conteúdo em si, demonstrando ser esta uma das possíveis estratégias a serem utilizadas na prática do professor.

Consideramos importante ressaltar que o processo de formação continuada, proporcionado pelas discussões e reflexões coletivas sobre as diversas temáticas abordadas no 
âmbito do Programa EDUCIMAT também contribuiu para o estabelecimento de relações entre as TIC e as práticas educativas a que chegaram os sujeitos investigados.

Partindo das perspectivas do uso das TIC, como recursos pedagógicos em situações de ensino de Ciências e Matemática manifestadas pelos professores-alunos, é possível considerar - à luz do que Imbernón (2006) chama de conhecimento profissional especializado - que o professor precisa cuidar de três aspectos importantes que são, a nosso ver, mutuamente inclusivos: o (re)conhecimento dos recursos tecnológicos no seu espaço de atuação, as experiências particulares na utilização de tais recursos e as experiências de ensino em que essas ferramentas estejam inseridas.

A experiência formadora vivenciada pelos professores-alunos trouxe, com efeito, interpretações que incidem sobre a própria formação docente. Por terem a oportunidade de experimentar a modalidade a distância por meio do AVA para formar-se continuamente, os sujeitos investigados atribuíram sentidos de constituir-se docente por meio da diversidade de ideias oferecidas e tecidas em conjunto, em um espaço compartilhado entre profissionais que trocam, colaboram e aprendem entre si.

Os sujeitos veem o espaço virtual como forma de compartilhar as dúvidas e as experiências docentes com outros professores, e, juntos, comporem uma rede de aprendizagem em que entrelaçam os diversos conhecimentos dos diversos participantes, com vistas à contínua formação.

Joana, ao vivenciar a dinâmica do curso, explicita indícios de ter compreendido o AVA como um espaço de formação que possibilita trabalhar e aprender coletivamente. Em suas palavras:

\begin{abstract}
Eu comecei a gostar do curso porque era uma forma de eu entrar em contato com outros colegas bem distantes. Durante o curso, acabamos percebendo que muitos dos nossos problemas também são problemas de outras localidades, de outros professores. Então, tem alguém para compartilhar. Sabemos que não resolvemos os problemas de sala de aula do dia para a noite, mas pelo menos temos alguém pra dividir, sugerir, para chorar as mágoas! Então, eu vi essa oportunidade lá, de estarmos juntos, aprendendo a trabalhar em grupo, discutindo sobre nossas dificuldades e desafios, além de podermos aprender não só com aqueles que estão ao nosso redor.
\end{abstract}

Joana, ao manifestar-se com relação à oportunidade proporcionada pelo curso no ambiente de estar junto, aprendendo a trabalhar em grupo, discutindo sobre dificuldades e desafios de sua prática docente, revela-se motivada a desenvolver sua formação em cursos dessa natureza, nos quais pode interagir em grupos colaborativos em que troca, compartilha, sugere.

A respeito de grupos colaborativos, Ferreira (2006, p.152) declara que, quando o professor participa de grupos como esse, percebe sua participação como fonte de aprendizagem. Desse modo, o grupo, para ele, torna-se o contexto no qual são criadas oportunidades de explorar e questionar seus saberes e práticas, bem como conhecer saberes e práticas de outros professores. Portanto, Joana, ao compartilhar seus saberes com o grupo, teve a oportunidade de explorá-los, além de conhecer e aprender sobre/com a prática de outros colegas professores.

É importante ressaltar que, para um AVA contribuir para o desenvolvimento de trabalhos colaborativos, assim como tornar-se um espaço de formação para professores de Ciências e Matemática, há a necessidade de planejar estratégias que favoreçam a construção coletiva do conhecimento em que todos - sem hierarquias - possam ensinar e aprender uns com os outros. 
Nessa perspectiva, buscar a contínua formação por meio da diversidade de ideias em rede digital é - além de apropriar-se das ferramentas midiáticas em prol da aprendizagem de modo crítico e reflexivo - buscar ser um sujeito coletivo num tempo de alta velocidade de informação e (trans) formação no espaço escolar e fora dele, em que a colaboração passa a ser uma maneira eficaz dos profissionais enfrentarem os problemas e desafios da sua prática, diante desse contexto atual, de incertezas e constantes mudanças (FIORENTINI e NACARATO, 2005).

\section{CONSIDERAÇÕES FINAIS}

As características geográficas e socioeconômicas da realidade local, explicitadas no texto, são capazes de ilustrar e compreender parte do cenário amazônico. Os enfrentamentos evidenciados pelos professores-alunos tornam-se, no decurso dessa trama, indicativos que possam vir a contribuir com pressupostos fundamentais na elaboração, organização e operacionalização de cursos de formação a distância de professores de Ciências e Matemática nessa região. É possível considerar que o acesso à informação está associado às oportunidades de formação, na medida em que as informações necessárias à profissão parecem chegar até os professores, no momento em que eles estão inseridos em práticas de formação, o que significa dizer que informação e formação estão diretamente relacionadas.

Desse modo, os recursos das telecomunicações associados aos recursos computacionais, podem ocupar um importante lugar nessa relação. Além disso, passamos a compreender que, na Amazônia, o processo de interiorização requer a utilização das diversas modalidades de ensino, e há possibilidade de definir a forma mais adequada para cada contexto, a partir de pesquisas que podem ser realizadas em cada micro ou mesorregião, o que consideramos desejável antes de qualquer proposta lançada.

Nessa perspectiva, damos a conhecer a seguir algumas das proposições discursivas a que chegamos por meio dos recortes das histórias de vida dos professores-alunos que participaram desse processo investigativo.

Quanto às propostas de formação continuada que envolvam AVA, chamamos atenção para preocupações com: i) As características dos locais de acesso à internet e a sua qualidade de conexão. É importante verificar se o acesso será de forma gratuita ou não e em quais períodos esses locais estarão disponíveis para os professores. Há que tomar consciência da qualidade de conexão da rede nesses locais, para que seja possível, diante dessas informações, elaborar programação adequada à realidade do grupo; ii) A escolha de um AVA que seja "leve"(que não sobrecarregue a parte física ou lógica do computador e da internet, tendo em vista a qualidade de infraestrutura constatada) e de fácil manuseio para usuários pouco experientes no uso da informática, haja vista a observância de poucas ofertas de formação de professores no uso das tecnologias e da exclusão digital na região; iii) Um design educacional que promova um tempo de acesso ao ambiente que seja adequado ao contexto, para não incorrer em custos elevados para o professor, caso ele tenha que pagar um local para acessar o AVA, que desenvolva dinâmicas de atividades e interações, envolvendo ações dentro e fora do ambiente (lançando mão de outros instrumentos pedagógicos), permitindo a possibilidade de participação de todos (inclusive dos professores atuantes na zona rural). Com efeito, é importante, ao estabelecer o plano de curso, atentar para períodos espaçados entre os temas que serão abordados, assim como os prazos para realização das tarefas propostas, tendo em vista a possibilidade dos professores da zona rural se locomoverem, por exemplo, nos finais de semana à zona urbana mais próxima, para a participação interativa no AVA; um 
design educacional que contemple tanto aqueles que pouco têm acesso à internet quanto aqueles que, frequentemente, têm acesso;

Quanto a constituir-se docente num mundo marcado pelos avanços tecnológicos, destacamos: i) É preciso (re) conhecer os recursos tecnológicos do contexto de atuação, de modo a saber transitar criticamente entre eles, responsabilizando-se pelas representações das tecnologias educacionais que (re) produzem aos alunos; ii) É urgente favorecer a compreensão do papel das tecnologias educacionais como instrumentos de mediação para a aprendizagem ao longo da vida, não ignorando o caráter situado de onde e para quem se fala; iii) É importante apropriar-se criticamente das linguagens e códigos multimídias que fazem parte da realidade dos alunos e utilizá-las como ferramentas motivacionais para o desenvolvimento da aprendizagem.

A respeito de algumas políticas de indução com vistas a ofertas de formação docente, recomendamos: i) Comprometimento por parte das secretarias municipais e estaduais de educação, quanto à liberação e à oferta de condições mínimas necessárias ao professor para sua efetiva participação nesses espaços formativos; ii) Organização - por parte das secretarias de educação - de grupo de professores que já foram contemplados com processos formativos, de modo a dar continuidade, no formato em rede, à formação de outros professores em exercício que ainda não tiveram oportunidade de realizar o curso; iii) As instituições de ensino, ao ofertarem cursos de formação, é desejável que elaborem um diagnóstico do público alvo e de seu contexto, a fim de que possam buscar parcerias públicas ou não governamentais para promover infraestrutura adequada à formação.

Além dessas proposições, importa-nos destacar que os desdobramentos da experiência formativa para os professores-alunos, em nível de percepção, foram para além do reconhecimento de que precisam apropriar-se de tais ferramentas computacionais. Construíram uma teia em movimento com múltiplas ideias, ampliando suas percepções metodológicas quanto ao uso das tecnologias educacionais na prática docente. Diante dessa rede de ressignificação do vivido, pelos sujeitos, é possível inferir que quanto mais conhecimentos e domínios das tecnologias educacionais digitais o professor possuir, quanto mais ele terá facilidade de produzir estratégias de ensino de Ciências ou Matemática, em que as tecnologias estejam inseridas.

Sob outro ponto de vista, é possível perceber que a experiência formativa ao fazer parte da história de vida desses professores não significou somente uma aproximação tecnológica, mas também produziu diversos sentidos no âmbito de suas ações de ensino de Ciências e Matemática. Ao experimentarem um espaço de troca de experiências e de liberdade de expressão, construíram nexos com a sua sala de aula.

Os professores-alunos manifestam o reconhecimento do AVA como instrumento interativo de uma formação continuada a distância, vislumbrando a integração de uma rede de professores de Ciências e Matemática capaz de ser tecida pela diversidade de ideias. É importante destacar que promover interações em espaços formativos virtuais poderá desenvolver nos sujeitos o entendimento de produção de trabalhos colaborativos por meio desse espaço, instigando a postura de um sujeito coletivo, necessária aos profissionais do mundo pós-moderno.

Nesses termos, ao trazer para debate a formação a distância de professores de Ciências e Matemática, mediatizada por AVA, reafirmamos a compreensão de que este processo formativo significa, sobretudo, dar aos professores a oportunidade de acesso à contínua formação, de viver experiências de tomada de decisão, de narrar práticas docentes e de ajudar o outro e com o outro a solucionar as dúvidas que surgem durante o processo formativo e, 
ainda, de viver experiências em que a tecnologia da informática configura-se como instrumento mediador de suas aprendizagens.

Desenvolvemos o olhar qualitativamente positivo sobre o desafio da formação continuada apoiada pelas TIC, porque consideramos uma oportunidade de conhecimento e de aproximação delas, ainda que seja ultrapassando os vários obstáculos existentes. No presente, construímos a proposição de que vencer as atuais barreiras desse espaço geográfico amazônico é ter a possibilidade de tomar consciência e buscar posicionar as TIC a serviço da comunidade local e não o inverso. É sentir-se, como Freire (2007), alegre em conhecer-se condicionado, mas capaz de ultrapassar o próprio condicionamento.

\section{REFERÊNCIAS}

ALMEIDA. M. E. B. Educação a distância na internet: Abordagens e contribuições dos ambientes digitais de aprendizagem. Educação e Pesquisa, v. 29, n. 2, p.327-340, jul-dez. 2003.

A construção compartilhada de significados em projetos de educação a distância. In: VALENTE, A; ALMEIDA, M. E. B. (Orgs). Formação de educadores a distância e integração de mídias. São Paulo: Avercamp, 2007.

ASSMANN, H. A metamorfose do aprender na sociedade da informação. revista ciência da informação. V.29. n2. Brasília mai/ago.2000.

CONNELly, F. M. CLANDININ, D. J. Relatos de Experiência e Investigación Narrativa. In: LARROSA, J. (Org.) Déjame que te cuente: ensaios sobre narrativa e educación. Barcelona: Alertes, 1995.

FERRAROTTI, F. Sobre a autonomia do método biográfico. In: NÓVOA, A; FINGER, M. (Orgs.) $O$ método (auto) biográfico e a formação. Lisboa: Ministério da Saúde, Departamento dos Recursos Humanos da Saúde, Centro de formação e Aperfeiçoamento Profissional, 1988.

FERREIRA, A. C. O trabalho colaborativo como ferramenta e contexto para o desenvolvimento profissional: compartilhando experiências. In: NACARATO, A. M. (Org.). A formação do professor que ensina Matemática: perspectivas e pesquisas Belo Horizonte: Autêntica, 2006.

FIORENTINI, D. NACARATO, A. (Org.). Cultura, formação e desenvolvimento profissional de professores que ensinam matematica: investigando e teorizando a partir da prática. São Paulo: Musa, Campinas: GEPFPM-PRAPEM-FE/UNICAMP, 2005.

FREIRE, P. Pedagogia da Autonomia: Saberes necessários à prática educativa. 33 ed. São Paulo: Paz e Terra, 2007 (Coleção Leitura).

GREEN, B. BIGUM, C. Alienígenas na sala de aula. In: SILVA, T.T (Org.). Alienígenas na sala de aula: uma introdução aos estudos culturais em educação. Petrópolis: Vozes, 2001.

IMBERNÓN, F. Formação docente e profissional: formar-se para a mudança e a incerteza. $6^{\mathrm{a}}$ Ed. São Paulo: Cortez, 2006. (Coleção Questões da Nossa Época)

JOSSO, M. C. Experiências de vida e formação. São Paulo: Cortez, 2004.

MEIRELLES, J. O livro de ouro da Amazônia. $5^{\text {a }}$ ed. Rio de Janeiro: Ediouro, 2006.

MOITA, M. C. Percursos de formação e trans-formação. In: NÓVOA, A. (Org.) Vidas de professores. 2 ed. Lisboa: Porto, 2000.

MORAES, M. C. O paradigma educacional emergente. 10 ed. Campinas: Papirus, 1997 (Coleção Práxis).

MORAES, R. GALIAZZI, M. C. Análise textual discursiva. Ijuí: Unijuí, 2007. 
SACRISTÁN, J. G. Educar e conviver na cultura global: as exigências da cidadania. Porto Alegre: Artmed, 2002.

SANTOS, B. S. Um Discurso sobre as Ciências. 3 ed. São Paulo: Cortez, 2005.

SILVA, A. S. S. Formação continuada de professoras de infância no Baixo Tocantins: concepções de criança [infância] e interdisciplinaridade. 2005. 103f. Dissertação (Mestrado em Educação em Ciências e Matemáticas) - Universidade Federal do Pará, Belém, 2005. 